\title{
Reading as Multi-Tasking: Unravelling Invisible Cognitive Processes in Reading
}

\begin{abstract}
When we read a text, several processes take place in our mind simultaneously. As we know, the first is the visual process which enables us to read graphic marks or letters that make words on paper or on screen. The writer's words, phrases, clauses, and sentences fall onto the reader's eye screen. This, as we know, happens almost automatically and effortlessly unless the handwriting is illegible. As soon as words fall onto our eyes, the process of interpretation begins. A competent reader, if s/ he is a competent user of the language as well, does several things synchronously. S/he mentally registers the speaker's use of norm-deviating and norm-approximating features. An expert reader is sensitive to all these features as well as grammatical, semantic, pragmatic, and cultural subtleties and nuances. Each of these features deserves an independent treatment and is worth a separate research project. The present paper focuses on appropriate use of vocabulary or use of appropriate vocabulary in writing. Understandably, not every writer is a proficient user of the language and so when a competent user of the language reads a text produced by a not-so-competent writer, the former goes through several processes such as (1) identification of an inappropriate word or expression, (2) crowding of synonyms, (3) clustering or bunching of synonyms, (4) intergroup competition of synonyms, (5) de-crowding by less appropriate bunch(es), (6) intra-group competition of synonyms, (7) selection of an appropriate word, (8) de-crowding by some items of the chosen group, (9) erasure of the inappropriate word used by the writer, and (10) replacement of the inappropriate word with what the reader thinks is an appropriate word or phrase. We can group these ten processes into three main categories-catapulting, centripetal process and centrifugal process.
\end{abstract}

Key words: Spotting/detecting, crowding, clustering, competing, selecting, erasing, replacing; catapulting, centripetal and centrifugal processes

\section{Nature of reading skills}

As we know, reading is a receptive and interactive skill. In fact, reading is not only a receptive but also a productive skill because when we read, we produce meanings and messages. That is why my interpretation of a text may differ from your interpretations of the same text. In this sense, a reader is not just a receiver of a meaning or message but a constructor of a meaning or message. Reading is a process of meaning making. When we read a text, the text interacts with us. It is not only the reader who interacts with the text. While reading, we anticipate certain linguistic items and moves. Sometimes texts flout our expectancies. O' Henry short stories usually

$140 \quad$ Journal of NELTA, Vol 21 No. 1-2, $\quad$ December 2016 
have a surprise ending. The unexpected endings of his stories surprise us. However, the unexpected endings offer us a satisfying feeling. Thus reading is a process that arouses expectations. It is a process in which we need to adjust our interpretations within the framework of fulfilled or unfulfilled predictions. Reading skills enable readers to decode texts and discover meanings.

\section{Reading as a guessing game}

As we have noted above, reading is a receptive, interactive and productive skill. We interpret things in our own way. We interact with the text we are reading. The text we are reading also interacts with us. When we read a text, we produce meanings and messages. Reading is a process, a journey into the unknown. Now you are reading this present sentence. While reading this sentence, you anticipate the next sentence. Your prediction may or may not come true. For example, when we read a typical $\mathrm{O}^{\prime}$ Henry story, we expect one thing to happen, but another unexpected thing happens. Let us cite the example of James Thurber's Unicorn in the Garden. The story goes like this:

One morning, a man tells his wife that he saw a unicorn in their garden. The wife does not believe him; she says a unicorn is a mythical beast and calls the husband a "booby" and threatens to put him in "a booby hatch". When the husband goes back to the garden she telephones the police and a psychiatrist and asks them to bring a straight-jacket.

At this point, we predict that the police and the psychiatrist will take the man to a lunatic asylum. But, the man turns the tables when he says that he did not tell his wife that he had seen a unicorn. The police and the psychiatrist think that it is the wife who is crazy and so they take her to a mental hospital.

Reading is a guessing game. We guess the meanings of unfamiliar words. The physical, psychological and linguistic contexts help us in our guesses. Let us illustrate this point with the help of Unicorn in the Garden. Our students may not know the words 'booby' and 'booby hatch' in the story. However, they do not have to rush to a dictionary every time they come across a new word. The situation in the story can help them. There are other words in the story that can help them. Words like 'police', 'psychiatrist', 'crazy' 'jay bird' and 'strait-jacket' help them to understand the words 'booby' and 'booby hatch'. Students follow certain steps in the process of understanding such new words. First, they do not think these two words are positive; they are negative in their meanings. Then, they zoom in and conclude that a 'booby' means 'a crazy person' and a 'booby hatch' means 'a lunatic asylum'.

Thus we understand the local meaning of a sentence or expression in the context of the global meaning of the story. Usually, a global meaning refers to the overall general meaning of a text. Thus when we ask a question about the moral of a story, we look for its global meaning.

\section{Reading as multi-tasking}

Reading was once considered a passive skill because it was thought that the reader was a receiver and was not required to do anything. The idea was that things were done to the reader, that s/he was an object and not a subject. Subsequently, it was described as a receptive and active skill. I consider it a productive skill because as readers we produce meanings and draw messages. It is an interactive skill; readers interact with writers and their words. It is 
a proactive skill; on the basis of what the writer has already said, readers can predict. This is very similar to our predictions while we are listening. Reading is a reactive skill; we react to what the writer has said. We may partly agree or fully agree; we may partly disagree or completely disagree. We use our knowledge of the world, knowledge of the language and knowledge of the rules of logic to produce meanings, to predict things, and to agree or disagree. It is a continuous process of meaning making. When we read a text, we think of the writer's choice of words and choice of grammatical structures. Simultaneously, we sense, recognize, interpret, evaluate, appreciate, sympathize, empathize, accept, reject, agree, disagree, connect, correct, question, select, filter, personalize, generalize, particularize, organize, reorganize, anticipate and recollect, and so on.

Let me take up the function of recollection. Reading is a re-collective skill. While we are reading, we may remember a whole bunch of things. Let me substantiate this point with examples of interlingual taboo words. For instance, when a writer writes in English, s/he may occasionally use words that resemble some taboo words in our first language (Mahmoud 2000 \& Patil 2006). In such a case, we are reminded of those words and are momentarily distracted from the act of reading. We can call this language transfer (Odlin, et al. 1989 \& Mahmoud 2002).

Japanese students, for example, hesitate to pronounce and read the English words mango and chin because they sound like the Japanese words manko and chin or chinpo, which refer to those female and male body parts respectively, which even the most isolated primitive people would cover with tree leaves. The English word mango (a fruit)in Japanese variety of English sounds like manko (female private body part)and that of the word chin (the lower end of the face) sounds like chin (male private body part).

In this context, it is worth noting that school textbook writers 'purify' teaching materials by deleting or at least replacing taboo words with euphemistic expressions. The issue of taboo expressions is of vital significance in the context of teaching English as a second or foreign language, especially in Asian countries. Textbook writers delete 'objectionable' material from a work of literature to 'purify' it and to make the selection 'clean'. That is what Bowdler did in his Family Shakespeare. He removed or modified everything that was offensive and brought out a children's edition of William Shakespeare. Similarly, our textbook writers follow some guidelines given to them for selecting and editing materials. School boards, university boards, parents and governments expect them to select 'good', 'clean', 'pure' materials and to 'purify' the originally 'impure' materials. It is usually quite easy for the materials writer to follow the guidelines and produce 'chaste' teaching materials. It is a physical, visible process and hence easy to follow.

Since there are no obscene and vulgar words in school textbooks, the issue here is not that of offensive words in the language that is being taught. In other words, the issue is not Arabic taboo words in Arabic reading materials or English taboo words in English language textbooks. Here we are talking about interlingual taboo expressions. This subject is obviously of potential interest from the point of view of teaching English as a second or foreign language, and can be usefully discussed only if serious conferences are prepared to hear such words in obviously serious and relevant contexts. Now, the question is: What is an inter-lingual taboo expression? An inter-lingual taboo expression is a normal, non-taboo expression in one language that resembles the 
pronunciation of a taboo expression in another language.

But how can we control reading processes, which are psycholinguistic guessing games? How can we prevent the learners from associating words and expressions in one language with those in another? For example, how can we prevent Japanese learners from remembering the Japanese word manko when they come across the English word mango? What can we do when Vietnamese learners come across the English word tea and remember the Vietnamese homophone that refers to the baby-feeding parts of a woman's anatomy? I suppose every language has some taboo words that sound like non-taboo words in English. In Arabic too there are taboo words that sound like the English words ear, unique, maniac, bus, noon, nick, etc. Smith (1987) cautions us about the use of such words in an Arab classroom: "The following English words sound similar to vulgar words in Arabic, and sensitive teachers should avoid them if possible: zip, zipper, air, tease, kiss, cuss, nick, unique." (p. 154). Thus it is in the teacher's hands to avoid saying such sentences as: "Lend me your ears. I want to tell you a unique story. The police were looking for a criminal maniac. They travelled by a special bus and reached a village. She was having a free noon when the police nicked (arrested) her. But when Arab learners read the following passage, they may regress several times because the passage contains words that sound like vulgar and obscene words in their language. Here is a made up example:

She'llbe travelling by a uniquebus that doesn't pollute the air to a place that doesn't have a zip code. She'll be accompanied by a maniac who has stolen some bowls of shells.
My experience of teaching Arab learners confirms my belief that most Arab readers of the above passage regress several times and linger on certain words due to their resemblance with vulgar and obscene words in Arabic. If each regression takes roughly two seconds, and nine regressions are made per three lines, then on an average page of 30 lines, one minute thirty seconds are wasted. Consequently, reading speed and comprehension slow down.

People generally tend to regard reading as a passive process that just happens rather than as a skill that is essential for effective communication. Yet in reality effective reading is a skill that needs to be developed as a prerequisite for successful speaking and writing. Reading involves a simultaneous orchestration of syntactic, semantic, and pragmatic skills. Let me take up these points one by one.

One, when we read, we are sensitive to the syntax used by the writer. One case in point is syntactic ambiguity. For example, in the following case the reader has to understand whether the writer is talking about guests as a nuisance or visits as a nuisance when he says, 'Visiting guests can be a nuisance.'

The sentence is ambiguous if and when stripped of its context. The reader has to interpret it in the context of the preceding discourse. Literature abounds in examples of ambiguity of different types. A reader has to exploit the conventions of literary creation, and grammatical, semantic and pragmatic resources to interpret what the writer is saying. Let us look at the following examples from Trask and Mayblin (2009, p. 126):

Susie had a shower after she got up.

After she got up, Susie had a shower.

After Susie got up, she had a shower.

She had a shower after Susie got up. 
Two, when we read, we are sensitive toconnotation of words, not just their denotation. Words have significances and values. The value of a word depends on the context in which it is embedded. Thus when Robert Frost says, "The woods are lovely, dark and deep, but I have promises to keep, and miles to go before I sleep, and miles to go before I sleep!" he is talking about the literal woods, miles and sleep; but more importantly, he is also talking about metaphorical woods, miles and sleep, about his obligations, about the journey of life and about death. It is a two-tier or perhaps a multi-tier communication. Such multi-level communication occurs in everyday situations too. An intelligent listener understands the complexity of the whole process and interprets utterances using knowledge of the world, the language, and logic.

Three, when we read, we read thepragmatic forceof the writer's sentences. Let me illustrate this point. Once my neighbour, who was a diabetic, asked his daughter about his box of chocolate? The daughter replied, "Show me your diet sheet, please!" Now, the daughter could have said that she had eaten his chocolate or that she had hidden the box. The question is: what did the girl mean when she said that? What did the old man understand? Evidently, what the daughter meant was that being a diabetic he was not supposed to eat chocolate. When we read this dialogue between the old man and his daughter, we understand the locutionary force as well as the illocutionary force of the daughter's imperative sentence.

Four, we respond to what words say when they occur in the company of other words. We can say that words are known by the company they keep. Human beings seem to possess this innate ability to connect words. Words acquire their special meanings when we connect them with each other or when words connect themselves with each other. Let us look at the following examples given by Trask and Mayblin (2009: p 110):

(A) Susie took her coat off.

Susie took her coat off the peg.

(B) Natalie ran out of the room.

Natalie ran out of flour.

(C) Alice lost her toothbrush.

Alice lost her virginity.

Five, we read words and utterances in context. Human beings have the innate ability to connect events to a larger scheme of things or the context. In the absence of this schema it would be difficult to understand what the writer is talking about. Let me give an example to clarify the idea of schema. Let us imagine a situation where two people are talking about something. When a third person arrives, this is what he hears:

A: How did it go?

B: Not so bad. But I'm glad it's over.

A: Was it the last one?

B: Yes, for the time being.

Now what do we figure out? What are these conversational partners talking about? Are they talking about extraction of a tooth, a test or examination, a delivery of a child, etc? An intruder has no clue what they are talking about because he does not share the background knowledge. Thus effective listening needs background knowledge: knowledge of events, people involved, their motives, and knowledge of the world at large.

When we read a scripted telephone conversation, we see only what one person says; we do not have access to what the person at the other end says. The statements, questions, exclamations and commands uttered by the person in the written text 
help us guess what the absent interlocutor probably has said. Let us illustrate this point. Let us read (imagine we are hearing what we are reading) the following telephone conversation and fill in the gaps.

Miss Green: Hello? Yes, this is Professor Hunter's house. Yes, Miss Hunter is here. One moment please. (She gives the telephone to Mary Hunter). It's for you dear. I think, it's Dr. Smith.

Mary:Good morning. Yes, Miss Hunter speaking. Yes, Dr. Smith, I'm very well. Thank you. Yes, father's well too. He's excited this morning, but we'll look after him. What's that? Freda's in hospital? Yes, of course, I'll come. I wanted to stay with father, but it doesn't matter. Yes, I'll be there in an hour. Goodbye. (She cradles the telephone)

We can fill the gaps as follows:

Dr. Smith (Dials Professor Hunter's telephone number; the phone rings. Miss Green picks up the receiver and answers the call)

Miss Green: Hello?

Dr. Smith: Is that Professor Hunter's house?

Miss Green: Yes, this is Professor Hunter's house.

Dr. Smith: Is Miss Hunter at home? / Can I speak to Miss Hunter please?

Miss Green: Yes, Miss Hunter is here. One moment please. (She gives the telephone to Mary Hunter).

Miss Green (To Miss Hunter): It's for you dear. I think, it's Dr. Smith.

Mary: Good morning.
Dr. Smith: Good morning. I am Dr. Smith speaking. Am I talking to Miss Hunter please?

Mary: Yes, Dr. Smith. This is Miss Hunter speaking.

Dr. Smith: How are you, Miss Hunter?

Mary: Yes, Dr. Smith. I' very well. Thank you.

Dr. Smith: How's Professor Hunter?

Mary: Yes, father's well too. He's excited this morning, but we'll look after him.

Dr. Smith: I'm sorry to tell you that Freda's in hospital.

Mary: What? Freda's in hospital?

Dr. Smith: She remembers you. Can you come to the hospital please?

Mary: Yes, of course, I'll come. I wanted to stay with father, but it doesn't matter.

Dr. Smith: Please come as early as possible.

Mary: Yes, I'll be there in an hour.

Dr. Smith: Thanks and good bye.

Mary: Goodbye. (She cradles the telephone)

Words have context-sensitive personalities. Words have signification in isolation, but they acquire value in contexts. Let us read the following paragraph in which the authors of this article have used the nonsense word zreastra. When we read this word in isolation, we do not know what it means, but when it occurs in a context, we can interpret it almost accurately. We may not understand it at its first occurrence; however; however, as we progress in our reading, we are able to narrow its scope, zoom in and interpret it correctly: 
We see many international travellers buying zreastras from Duty Free shops inside departure and arrival terminals at airports. They buy zreastrasfor themselves or as gifts for their friends and acquaintances. In the past, zreastras were available in attractive and luring packets. These days, zreastrasare available in packets, which bear horrifying pictures, because World Health Organization and governments have made it mandatory for zreastra manufacturers to have such terrifying pictures on zreastracartons. Millions of people across the world are addicted to zreastras though they know zreastraing is injurious to health. However, because zreastracartons and packets carry a statutory warning that zreastraing is injurious to health, that it causes cancer, especially lung cancer, the number of zreastra buyers has gone down (Patil, et al. 2015, p. 120).

Or let us read this one:

I have a fleep with me every day. Thisfleep goes with me everywhere, and I consider it an indispensible part of my life. In appearance it offers an attractive contrast: one part is bright and shiny, the other quietly dull. My fleep outlasts the other parts of my wardrobe, and I can often wear it for several years. Being unobtrusive, it seldom goes out of style. Some people like a stretchy fleep but I prefer the traditional kind. The leather of my fleep is soft and supple so that it gives with every movement of a part of my body. This fleep is very important to my wellbeing, for without it my trousers would come down. So every morning I buckle it around my waist and step forth to meet the world with a feeling of confidence.

Six, when we read something, we do not read words or lines alone; we read between and beyond words and lines. No wonder people say that speech is silver but silence is golden John Keats in his Ode on a Grecian Urn says that heard melodies are sweet, but those unheard are sweeter.

Now let me discuss the main idea of (1) detection of error, (2) crowding of synonyms, (3) clustering or bunching of synonyms, (4) intergroup competition, (5) de-crowding of less appropriate bunch(es), (6) intra-group competition, (7) selection of the most appropriate word or expression, (8) de-crowding of less appropriate synonymous words from the chosen bunch, (9) erasure of the wrongly used word or expression, and (10) replacement of the wrong word with the right one. When we come across a wrongly used word, detecting stage is usually followed by crowding, clustering and selecting stages. In other words, crowding, clustering and selecting precede erasing and replacing stages. Here, we must remember that detecting, crowding, clustering, erasing and replacing are not distinctly sequential or linear stages as if these were loops of a chain. These stages are like the colours of a rainbow. We don't know where one colour ends and another begins.

The words that crowd, that swarm, and then cluster together on the mental map are predominantly paradigmatic or collocation choices. We read a wrong word or a wrong use of a word, and within a fraction of a second some other words crowd around the one which has been wrongly used or has been used in a wrong position. There is a centripetal movement of semantically and grammatically similar words. Within a millisecond the mind erases the wrong word

$146 \quad$ Journal of NELTA, Vol 21 No. 1-2, $\quad$ December 2016 
and superimposes the right word from among the crowding words. As soon as the erased word is replaced by an accurate and appropriate word, the remaining members of the crowding group of words flee. There is a rapid centrifugal movement.

The crowding, erasure and substitution happen within a millisecond. In some cases, there is no crowding because there is only one available or suitable alternative as in the case of the first example given below. In other cases, there is crowding because there are more than one suitable candidate as in the second example listed below. In a few cases, there may not be any crowding; there may just be a mere repositioning of constituent parts. It may be a repositioning of a single item or multiple items as in the third and fourth examples.

(1a) Like their ancestors the tribals had no control over the forest.

(1b) Unlike their ancestors the tribals had no control over the forest.

(2a) Pratab Goldar owns a village. He spoils all rules and regulations.

(2b) Pratab Goldar owns a village. He spoils all rules and regulations.

(2c) Pratab Goldar owns a village. $\mathrm{He}$ all rules and regulations.

(2d) Pratab Goldar owns a village. He violates, breaks, flouts, disrespects, disregards, transgresses all rules and regulations.

(2e) Pratab Goldar owns a village. He violates/breaks/flouts, all rules and regulations.

(2f) Pratab Goldar owns a village. $\mathrm{He}$ violates all rules and regulations. (3a) Now how the rhetoric in animal communication can be understood?

(3b) Now how can the rhetoric in animal communication be understood?

(4a) Mulk Raj Anand was among the first to speak of the margins... who were thrown to the margins of society through his writings.

(4b) Mulk Raj Anand was among the first to speak through his writings of the margins... who were thrown to the margins of society.

Now let me illustrate the processes of detecting, crowding, bunching/clustering, competing, de-crowding, erasing and replacing. Let me take up the second example. First our mind quickly detects that 'spoils' is wrongly used in this sentence. It is a wrong choice, a wrong collocation. Immediately, other words like 'breaks', 'disregards', 'transgresses' 'violates', 'disrespects', and 'flouts' vie for the position. Each one of these words seems to be saying, "Use me. I am available". They try to swarm around that coveted position. Then immediately they cluster into bunches like 'breaks, violates, flouts' as one group, 'disrespects' and disregards' as another bunch, and 'transgresses' as an independent candidate. Within a millisecond, our mind makes a decision and chooses one of these bunches. As soon as we choose one bunch, other bunches run away. If we choose 'breaks-violates-flouts' bunch, the 'disrespects-disregards' bunch disappears, and so does the word 'transgresses'. Now, out of the chosen bunch, depending upon the formality-informality axis, solidaritypower axis, and the required register, our mind selects either 'breaks' or 'violates' or 'flouts'. The moment we choose, 'violates', the other candidates vanish. The word 'spoils' is then replaced with either 'breaks', or 'flouts', or 'violates'. 
These processes of detecting, crowding, competing, selecting, de-crowding and replacing can be reduced to catapulting, centripetalizing and centrifugalizing. I use catapulting to refer to detecting a wrong word as well as choosing a right one. I use centripetalizing to refer to crowding, competing and replacing, and centrifugalizing to refer to de-crowding.

It took me about fifteen minutes to write about the whole process. But it takes a millisecond for the process to happen. It happens like a flash of lightning, within no time. Now let us do some more examples of (a) detecting, catapulting, erasing, and replacing, (b)detecting, crowding, bunching, inter-bunch competing, interbunch de-crowding, intra-bunch competing, intra-bunch de-crowding, erasing and replacing, and (c) repositioning of single or multiple elements.

(A) Detecting, catapulting, erasing and replacing

Single Alternative

(1a) This simple better economy was later replaced by currency-oriented economy.

(1b) This simple barter economy was later replaced by currency-oriented economy.

(2a) Bashai Tudu in 'Agnigarbha' by Mahasweta Devi rejects to surrender.

(2b) Bashai Tudu in 'Agnigarbha' refuses to surrender.

(3a) Mahasweta Devi comments on the insensibility of the system towards tribals. (3b) Mahasweta Devi comments on the insensitivity of the system towards tribals.

(4a) It is impracticable to categorize Mahasweta Devi under one title.

(4b) It is impossible to categorize Mahasweta Devi under one label.

(5a) There are difficulties in identifying certain alphabets.

(5b) There are difficulties in identifying certain letters.

(6a) These waves have been discussed further in this paper.

(6b) These waves have been discussed later in this paper.

(7a) The disorganized and scattered mass of ideas can be given shape latter.

(7b) The disorganized and scattered mass of ideas can be given shape later.

(B) Detecting, crowding, bunching, interbunch competing, inter-bunch decrowding, intra-bunch competing, intrabunch de-crowding, erasing and replacing

Multiple Alternatives

(1a) In the course of the novel, the boy is encountered by the politician and his goons.

(1b) In the course of the novel, the boy is killed / murdered by the politician and his goons.

(2a) The rebellions indicate interchange between the mainstream culture and the subaltern culture.

(2b) The rebellions indicate enmity, animosity, rivalry, antagonism 
between the mainstream culture and the subaltern culture.

(3a) Mahasweta Devi comments on the status of the tribals.

(3b) Mahasweta Devi comments on the condition/plight/predicament of the tribals.

(4a) The government and the missionaries were indifferent to the claims made by the Mundas. The alteration was to drive away those in authority.

(4b) The government and the missionaries were indifferent to the claims made by the Mundas. The alternative/ option/choice was to drive away those in authority.

(5a) Even today villagers are under the spell of village owners.

(5b) Even today villagers are under the domination/control/subjugation of village owners.

(6a) Their answers say that they know the grammatical rules.

(6b) Their answers indicate/suggest/imply that they know the grammatical rules.

(7a) This bespeaks for pedagogical reforms.

(7b) This implies/suggests/necessitates/ callsfor/requires/entails pedagogical reforms.

(8a) The narration is disturbed.

(8b) The narration is disrupted/ruptured/ fractured.

(9a) The narrative sways from the subaltern to the mainstream society.

(9b) The narrative swings/oscillates from the subaltern to the mainstream society. (10a) The situation/ position of the tribals became like King Lear.

(10b) The condition/plight/predicament of the tribals becamelike that of King Lear.

(11a) Only one rhetoric is focused on and the benefits of alternate rhetoric are often overlooked.

(11b) Only one rhetoric is focused on and the benefits of alternative/other rhetoric are often overlooked.

(12a) Extrinsic motivation is an outward push.

(12b) Extrinsic motivation is an outside, external push.

(13a) They were asked to write a piece of narrative writing.

(13b) They were asked to produce/come up with a piece of narrative writing.

(C) Repositioning

(i) Repositioning of a Single Item

(1a) Very rarely Mahasweta Devi has talked about urban life.

(1b) Very rarely has Mahasweta Devi talked about urban life.

(ii) Repositioning of Multiple Items

(1a) Ranade, Agarkar, etc. advocated the importance of education as liberating power from the clutches of unjust systems.

(1b) Ranade, Agarkar, etc. advocated the importance of education as a power liberating people from the clutches of unjust system.

(2a) In some cases Mahasweta Devi makes use of supernatural assumptions normally believed in by Adivasi cult to approximate their experiences. 
(2b) In some cases, to approximate their experiences, Mahasweta Devi makes use of supernatural assumptionsnormally believed in by Adivasi cult.

(3a) The questionnaire that we had distributed of twenty open ended questions...

(3b) The questionnaire consisting of twenty open ended questions that we had distributed...

\section{Pedagogical implications}

This analysis helps us to design and administer activities that enrich learners' vocabulary, to sensitize learners to semantic nuances, and to develop their collocation competence. Teachers can offer samples of improper choice of words covering single as well as multiple alternatives. Similarly, we can give them sentences which contain segments that are placed in wrong positions. Learners can work in pairs or groups and suggest alternatives and justify their choices in the light of contextual factors such as solidarity principle, power principle, cultural propriety, pragmatic considerations such as politeness, conversational cooperation, etc.

\section{Conclusion}

Precise vocabulary is one of the keys to good speaking and writing. The richer our vocabulary and the greater the precision with which we are able to use it, the better will be the talk we give or the letter we write. A larger and richer vocabulary is very important. It makes our speech and our writing easier and more effective. Every word has a personality and if we do not respect it, words will take revenge and if we continue disrespecting them, they will take revenge with vengeance. A good conversationalist or speaker develops a feeling for words and selects the right synonym or antonym. For example, a price is sometimes high, sometimes exorbitant and sometimes astronomical. A salary can be fat, handsome or seductive.

When we listen to a speaker or read a paper or thesis, we sometimes come across wrong use of a word or use of a wrong word. When that happens, several processes happen in a millisecond. Our mind immediately identifies the problem and places alternatives before us. These alternatives rush to us in a crowd and form their families or communities. These families or communities compete among themselves. As soon as our mind chooses the best member of a particular family, three things happen. The wrong word disappears; the rejected word families disappear; other members of the chosen word family disappear. The competition is over. All this happens within a fraction of a second.

\section{References}

Mahmoud, A. (2000). Interlingual errors of Arab students: A course-book for education majors (Unpublished Manuscript). Muscat: Sultan Qaboos University.

Mahamoud, A. (2002). Interlingual transfer of idioms by Arab learners of English. The Internet TESL Journal, 8 (12).

Odlin, T., Long, M. \& Richards, J. (1989). Language transfer: Cross-linguistic influence in language learning. Cambridge: Cambridge University Press.

Patil, Z. N. (2006). Inter-lingual phonology and the reading process: Some reading problems of Arab learners of English. Proceedings of the International Conference on ELT. Muscat: Sultan Qaboos University. 
Patil, Z. N. \& Patil K. (2015). The role of context in comprehension. NELTA ELT FORUM (115-121). Kathmandu: Nepal EnglishTeachers' Association

Smith, B. (1987). Arabic speakers. In M. Swan \& B. Smith, Learner English (pp. 142-157). Cambridge: Cambridge University Press.

Trask, R. L. \& Mayblin, B. (2009). Introducing Linguistics: A Graphic Guide. USA: Totem Books.
The author: Professor Patil has delivered sponsored keynote addresses in Bangladesh, Canada, China, Dubai, Germany, India, Indonesia, Japan, Korea, Nepal, Oman, Philippines, Singapore, Thailand and Turkey; authored many reference books and textbooks and published eighty articles in national and international journals. He worked as an English Language Specialist and Senior English Language Advisor in Vietnam and Japan respectively for six years. 